\title{
Early neuromuscular blockade for acute respiratory distress syndrome: a systematic review with meta- analysis and trial sequential analysis
}

\section{Xinchang Zhang}

Nanjing University of Chinese Medicine

Dekang Liu

Nanjing University of Chinese Medicine

Feifei Ge

Nanjing University of Chinese Medicine

Xiuping Xu ( $\nabla$ xiupxu@126.com )

Nanjing University of Chinese Medicine https://orcid.org/0000-0003-3950-3425

Xiaowei Guan

Nanjing University of Chinese Medicine

\section{Research}

Keywords: Neuromuscular blockade, Acute respiratory distress syndrome, Mortality, Meta-analysis

Posted Date: May 29th, 2020

DOI: https://doi.org/10.21203/rs.3.rs-31867/v1

License: (c) (1) This work is licensed under a Creative Commons Attribution 4.0 International License. Read Full License 


\section{Abstract}

Background To assess the effect of neuromuscular blockade on outcomes in adults with acute respiratory distress syndrome who are receiving mechanical ventilation.Methods We searched from inception to 24 may 2019 in MEDLINE, EMBASE and CENTRAL. We included randomized clinical trials comparing early neuromuscular blockade to placebo or usual care in adults with moderate to severe ARDS (Pa02/FiO2 $\leq 150 \mathrm{mmHg})$. The primary outcome was 90 -day and 28-day mortality. Secondary outcomes included oxygenation, driving pressure, incidence of barotrauma and pneumothorax, ventilatorfree days at 28 days and ICU-acquired weakness by 28 days. In addition, a trial sequential analysis was performed.Results Four trials were included with a total of 1437 patients. For the primary outcomes, there was no effect of neuromuscular blocking agent (NMBA) on 90-day mortality [relative risk (RR) 0.91, $95 \% \mathrm{Cl} 0.72-1.15, \mathrm{p}=0.41$ ] or 28-day mortality [RR $0.55,95 \% \mathrm{Cl} 0.22-1.12, \mathrm{p}=0.08$ ], or ventilator-free days at 28 days [mean difference $(\mathrm{MD}) 0.86,95 \% \mathrm{Cl}-0.61-2.33, \mathrm{p}=0.25]$. NMBA improved PaO2/FiO2 at $72 \mathrm{~h}$ [MD $15.21,95 \% \mathrm{Cl} 1.90-28.52, \mathrm{p}=0.03$ ]. NMBA reduced the incidence of barotrauma [RR $0.55,95 \% \mathrm{Cl} 0.35-0.85$, $p=0.007$ ] and pneumothorax [RR $0.46,95 \% \mathrm{Cl} 0.28-0.76, p=0.002]$ and increased the driving pressure at 24 hours [MD 0.75, 95\% $\mathrm{Cl} 0.24-1.26, p=0.004$ ] and 48 hours [MD $0.75,95 \% \mathrm{Cl} 0.08-1.43, p=0.03$ ]. There is no statistically significant difference in ICU-acquired weakness by 28 days [RR $1.20,95 \% \mathrm{Cl} 0.72-1.98$, $\mathrm{p}=0.49]$. Conclusions In adults with moderate to severe ARDS treated with early neuromuscular blockade, oxygenation increase, incidence of barotrauma and pneumothorax are reduced, ICU-acquired weakness are not increased, but 90-day and 28-day mortality are not decreased. Further large-scale, multicenter studies are needed to confirm our results.Trial Registry PROSPERO (ID: CRD42019137832)

\section{Background}

Acute respiratory distress syndrome (ARDS) is a type of acute diffuse, inflammatory lung injury characterized by hypoxemia, decreased lung compliance and bilateral radiographic opacities [1]. Despite decades of research, efficient approaches for the treatment of ARDS are still limited [2]. Numerous pharmacological interventions have been associated with disappointing results [3-6]. Other treatment strategies, such as nitric oxide and corticosteroids, are able to improve clinical parameters, but they are not definitely associated with survival benefit $[7,8]$. Supportive care with mechanical ventilation to maintain gas exchange remains the mainstay of management [9].

Intriguingly, early continuous neuromuscular blockade in ARDS patients who are receiving mechanical ventilation was shown to be able to decrease mortality [10]. However, neuromuscular blockade hasn't been widely adopted and was weakly recommended in clinical practice guideline [11]. The main reason is that the clinical guideline was based on three trials originated from the same group of investigators in France $[10,12,13]$. Recently in United States, a larger-scale randomized controlled trial have been carried out to re-evaluate the therapeutic effects of early neuromuscular blockade in the management of ARDS [14]. According to the results, early neuromuscular blockade failed to decrease the mortality of ARDS patients at 90 days compared with usual care. Therefore, the benefit of adjunctive therapy with neuromuscular blocking agent (NMBA) in ARDS patients remains debatable. 
To provide an updated summary of the evidence, a systematic review and meta-analysis with trial sequential analysis was conducted to assess the benefit and risk of NMBA in the management of moderate to severe ARDS patients compared to placebo or usual care.

\section{Methods}

The protocol for this study was published in the online PROSPERO database (CRD42019137832) prior to the analysis. The protocol is available at: https://www.crd.york.ac.uk/PROSPERO/display_record.php? RecordID $=137832$

\section{Search and eligibility criteria}

We performed a search of electronic databases, Medline, EMBASE and the Cochrane Central Registry of Controlled Trials. All searches were conducted from inception through to May 24, 2019. The search terms are "acute respiratory distress syndrome", "ARDS" AND "neuromuscular blocking agents", "neuromuscular blockade", "atracurium", "cisatracurium", "pancuronium", "rocuronium"[15]. We searched for randomized clinical trials (RCTs) of adult patients with acute respiratory distress syndrome intubated in the first 48 hours and use of any NMBA in one arm of the study compared with another arm without NMBA (placebo or usual care). And at least one of the outcomes outlined below were reported. We applied no language restriction. We also conducted a manual search of reference lists of relevant primary studies and previous review articles. Additional articles or abstracts were retrieved by manually scrutinising the reference list of relevant publications.

\section{Study selection}

Figure 1 summarized the study selection process. Two authors (XCZ, XPX) independently screened abstracts for potentially eligible studies. Full-text reports were then assessed for eligibility. Disagreement during the review process was resolved by discussion with a third reviewer (XWG) and by consensus.

\section{Data extraction}

Two investigators (DKL, FFG) independently extracted information from each included trial. We extracted all available data as outlined in the protocol, including characteristics of the included studies, details of the population enrolled, details of the intervention including dose and regimen of NMBA and whether the comparison group received placebo or usual care. Driving pressure in the protocol that were not available in trial reports were calculated according to formula as follow.

$\mathrm{PEEP}_{\text {tot }}=$ external PEEP + intrinsic PEEP

Driving pressure $=\mathrm{P}_{\text {plat }}-\mathrm{PEEP}$ tot

\section{Risk of bias assessment}


Two investigators (XCZ, XPX) independently assessed risk of bias of the included trials according to the Cochrane risk of bias tool. Disagreements were resolved by discussion with a third reviewer (XWG) and by consensus. We adjudicated risk of bias across all predefined outcome measures, and overall risk of bias was adjudicated low only if all domains were assessed as low risk of bias.

\section{Outcomes}

Our primary efficacy outcome was mortality at day 90 and day 28. Secondary outcomes were PaO2/FiO2 ratio at 24,48,72 hours, driving pressure at 24,48 hours, incidence of barotrauma and pneumothorax, the ventilator-free days at 28 days and ICU-acquired weakness by 28 day after randomization.

\section{Trial sequential analysis}

In the present study, we performed the trial sequential analysis (TSA) to decrease the risks of random errors due to sparse data and calculate the optimal information size. In this TSA model, we estimated the required information size usinga $=0.05$ (two-sided), $\beta=0.20$ (power of $80 \%$ ) for primary and selected secondary outcomes. For primary outcome, a $20 \%$ relative risk reduction (RRR) and the control event proportions calculated according to trials included were used to calculate the optimal information size. TSA was performed using the trial sequential analysis v.0.9.5.10 beta (Copenhagen Trial Unit, Centre for Clinical Intervention Research, Rigshospitalet, Copenhagen, Denmark, available from www.ctu.dk/tsa).

\section{Grading the quality of evidence}

In the present study, we used the Grades of Recommendation, Assessment, Development, and Evaluation (GRADEpro GDT https://gradepro.org/) [16] to evaluate the quality of evidence. And evidences were categorized as high, moderate, low, and very low according to the quality of design, limitations, inconsistencies, indirectness, imprecision, and possible publication bias.

\section{Statistical analysis}

We used Review Manager 5.3 to calculate risk ratio (RR) with $95 \%$ confidence intervals $(95 \% \mathrm{Cl})$ for dichotomous variables and mean difference (MD) with $\mathrm{Cl}$ for continuous outcomes. We assessed for heterogeneity between studies by using $\chi^{2}$ statistic and the $R^{2}$ statistic $>30 \%$ indicating substantial heterogeneity). In cases of significant heterogeneity $\left(R^{2}>30 \%\right)$, a random-effects model was used; otherwise, a fixed-effects model was applied. We had too few studies to assess for publication bias by using a funnel plot or conventional statistical methods. We assessed statistical significance at $p<0.05$.

\section{Results}

\section{Search Results and Trial Characteristics}

Through electronic searches and from reading the references of potentially relevant articles, we identified 880 publications (Fig. 1). 25 studies were retrieved for detailed evaluation. We included 4 trials [10, 1214] (Table 1), which randomized a total of 1437 participants (NMBA, 724 [50.4\%]; Control, 713 [49.6\%]). 
Table 1

Characteristics of the included patients

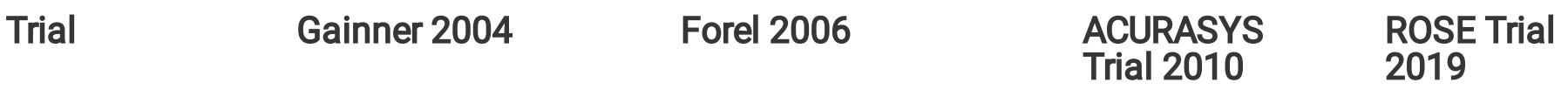

Populations

$\begin{array}{lllll}\begin{array}{l}\text { (1) Study } \\ \text { center }\end{array} & 4 \text { ICUs in France } & 3 \text { ICUs in France } & \begin{array}{l}20 \text { ICUs in } \\ \text { France }\end{array} & \begin{array}{l}48 \text { ICUs in } \\ \text { America }\end{array} \\ \begin{array}{l}\text { (2) Total } \\ \text { number of }\end{array} & 56(28 \text { vs. } 28) & 36(18 \text { vs. } 18) & \begin{array}{l}339(177 v s . \\ 162)\end{array} & \begin{array}{l}1006(501 \text { vs. } \\ \text { indude }\end{array}\end{array}$

included

patients

(NMBA vs

control)

\begin{tabular}{|c|c|c|c|}
\hline $\begin{array}{l}\text { (3) ARDS } \\
\text { definition }\end{array}$ & $\begin{array}{l}\text { American-European } \\
\text { consensus }\end{array}$ & $\begin{array}{l}\text { American-European } \\
\text { consensus }\end{array}$ & $\begin{array}{l}\text { American- } \\
\text { European } \\
\text { consensus }\end{array}$ \\
\hline
\end{tabular}

\begin{tabular}{|c|c|c|c|c|}
\hline $\begin{array}{l}\text { (4) Criteria for } \\
\text { moderate-to- } \\
\text { severe ARDS }\end{array}$ & $\begin{array}{l}\mathrm{PaO}_{2} / \mathrm{FiO}_{2}< \\
150 \mathrm{mmHg} \text { with } \\
\mathrm{PEEP} \geq 5 \mathrm{~cm} \mathrm{H} 2 \mathrm{O}\end{array}$ & $\begin{array}{l}\mathrm{PaO}_{2} / \mathrm{FiO}_{2} \leq \\
200 \mathrm{mmHg} \text { with } \\
\mathrm{PEEP} \geq 5 \mathrm{~cm} \mathrm{H} 20\end{array}$ & $\begin{array}{l}\mathrm{PaO}_{2} / \mathrm{FiO}_{2}< \\
150 \mathrm{mmHg} \\
\text { with PEEP } \geq \\
5 \mathrm{~cm} \mathrm{H} 2 \mathrm{O}\end{array}$ & $\begin{array}{l}\mathrm{PaO}_{2} / \mathrm{FiO}_{2}< \\
150 \mathrm{mmHg} \\
\text { with PEEP } \geq \\
8 \mathrm{~cm} \mathrm{H} 2 \mathrm{O}\end{array}$ \\
\hline (5) Age & 60.6 & 56.5 & 58 & 55.8 \\
\hline
\end{tabular}

Severity of illness at enrollment (mean \pm SD, NMBA vs control)

\begin{tabular}{|c|c|c|c|c|}
\hline (1) $\mathrm{PH}$ & $\begin{array}{l}7.33 \pm 0.10 \text { vs. } 7.35 \\
\pm 0.09\end{array}$ & $\begin{array}{l}7.32 \pm 0.14 \text { vs. } 7.35 \pm \\
0.11\end{array}$ & $\begin{array}{l}7.31 \pm 0.10 \text { vs. } \\
7.32 \pm 0.10\end{array}$ & $\begin{array}{l}7.32 \pm 0.10 \text { vs. } \\
7.32 \pm 0.10\end{array}$ \\
\hline $\begin{array}{l}\text { (2) } \mathrm{PaO}_{2} / \mathrm{FiO}_{2} \\
(\mathrm{mmHg})\end{array}$ & $\begin{array}{l}130 \pm 34 \text { vs. } 119 \pm \\
31\end{array}$ & $105 \pm 22$ vs. $125 \pm 20$ & $\begin{array}{l}106 \pm 36 \text { vs. } \\
115 \pm 41\end{array}$ & $\begin{array}{l}116.1 \pm 38.3 \\
\text { vs. } 115.8 \pm \\
40.1\end{array}$ \\
\hline $\begin{array}{l}\text { (3) } \mathrm{PaCO} 2 \\
\text { (mmHg) }\end{array}$ & $\begin{array}{l}48.3 \pm 9.0 \text { vs. } 47.4 \pm \\
11.3\end{array}$ & $\begin{array}{l}51.1 \pm 9.9 \text { vs. } 47.2 \pm \\
9.8\end{array}$ & $\begin{array}{l}47 \pm 11 \text { vs. } 47 \\
\pm 11\end{array}$ & $\begin{array}{l}44.1 \pm 10.2 \text { vs. } \\
43.8 \pm 12.0\end{array}$ \\
\hline (4) SAPS II & 43.6 & 48 & 48.5 & NA \\
\hline (5) SOFA & NA & NA & NA & 8.7 \\
\hline (6) APACHE III & NA & NA & NA & 104.4 \\
\hline
\end{tabular}

Intervention

NMBA, neuromuscular blocking agent; ARDS, acute respiratory distress syndrome; NA, not available; SAPS II, simplified acute physiology score II; SOFA, Sequential Organ Failure Assessment; APACHE III, acute physiology, age, and chronic health evaluation III 


\begin{tabular}{|c|c|c|c|c|}
\hline Trial & Gainner 2004 & Forel 2006 & $\begin{array}{l}\text { ACURASYS } \\
\text { Trial } 2010\end{array}$ & $\begin{array}{l}\text { ROSE Trial } \\
2019\end{array}$ \\
\hline NMBA group & $\begin{array}{l}\text { A bolus of } 50 \mathrm{mg} \\
\text { cisatracurium } \\
\text { followed by } \\
5 \mu \mathrm{g}^{-\mathrm{kg}^{-1}} \cdot \mathrm{min}^{-1} \\
\text { infusion for } 48 \mathrm{~h}\end{array}$ & $\begin{array}{l}\text { A bolus of } 0.2 \mathrm{mg} / \mathrm{kg} \\
\text { cisatracurium } \\
\text { followed by } 5 \mu \mathrm{g} \cdot \mathrm{kg}^{-} \\
{ }^{1} \mathrm{~min}^{-1} \text { infusion for } \\
48 \mathrm{~h}\end{array}$ & $\begin{array}{l}\text { A bolus of } \\
15 \mathrm{mg} \\
\text { cisatracurium } \\
\text { followed } \\
37.5 \mathrm{mg} / \mathrm{h} \text { for } \\
48 \mathrm{~h}\end{array}$ & $\begin{array}{l}\text { A bolus of } \\
15 \mathrm{mg} \\
\text { cisatracurium } \\
\text { followed } \\
37.5 \mathrm{mg} / \mathrm{h} \text { for } \\
48 \mathrm{~h}\end{array}$ \\
\hline Control group & $\begin{array}{l}\text { An infusion of } \\
\text { saline at a rate of } \\
4 \mathrm{ml} / \mathrm{h}\end{array}$ & $\begin{array}{l}\text { An infusion of saline } \\
\text { at a rate of } 4 \mathrm{ml} / \mathrm{h}\end{array}$ & $\begin{array}{l}\text { A bolus of } \\
15 \mathrm{mg} \text { placebo } \\
\text { followed } \\
37.5 \mathrm{mg} / \mathrm{h} \text { for } \\
48 \mathrm{~h}\end{array}$ & $\begin{array}{l}\text { Usual } \\
\text { treatment for } \\
\text { control group }\end{array}$ \\
\hline $\begin{array}{l}\text { Sedation } \\
\text { strategies in } \\
\text { control group }\end{array}$ & Deep sedation & Deep sedation & Deep sedation & Light sedation \\
\hline \multicolumn{5}{|l|}{ Outcomes } \\
\hline $\begin{array}{l}\text { (1) } 90-d \\
\text { mortality }\end{array}$ & NA & NA & $\begin{array}{l}56 / 177 \text { vs. } \\
66 / 162\end{array}$ & $\begin{array}{l}213 / 501 \text { vs. } \\
216 / 505\end{array}$ \\
\hline \multicolumn{5}{|l|}{$\begin{array}{l}\text { (NMBA vs. } \\
\text { Control }(n / N))\end{array}$} \\
\hline $\begin{array}{l}\text { (2) } 28-d \\
\text { mortality }\end{array}$ & $10 / 28,17 / 28$ & $5 / 18,10 / 18$ & $\begin{array}{l}42 / 177 \\
54 / 162\end{array}$ & $\begin{array}{l}184 / 501 \\
187 / 505\end{array}$ \\
\hline \multicolumn{5}{|l|}{$\begin{array}{l}\text { (NMBA vs. } \\
\text { Control }(\mathrm{n} / \mathrm{N}))\end{array}$} \\
\hline \multicolumn{5}{|c|}{ Oxygenation (mean \pm SD with (no), NMBA vs control) } \\
\hline $\begin{array}{l}\text { (1) } \mathrm{PaO} 2 / \mathrm{FiO} 2 \\
\text { at } 24 \text { hours } \\
\text { (mmHg) }\end{array}$ & $\begin{array}{l}159 \pm 48(28), 145 \pm \\
56(28)\end{array}$ & $\begin{array}{l}183 \pm 73(18), 146 \pm \\
47(18)\end{array}$ & $\begin{array}{l}164 \pm 72(172) \\
168 \pm 72(159)\end{array}$ & $\begin{array}{l}198.4 \pm 77.7 \\
(436), 189.2 \pm \\
76.8(408)\end{array}$ \\
\hline $\begin{array}{l}\text { (2) } \mathrm{PaO} 2 / \mathrm{FiO} 2 \\
\text { at } 48 \text { hours } \\
(\mathrm{mmHg})\end{array}$ & $\begin{array}{l}183 \pm 88(28), 139 \pm \\
42(27)\end{array}$ & $\begin{array}{l}205 \pm 73(18), 152 \pm \\
49(18)\end{array}$ & NA & $\begin{array}{l}198.0 \pm 73.4 \\
(381), 193.2 \pm \\
79(348)\end{array}$ \\
\hline $\begin{array}{l}\text { (3) } \mathrm{PaO} 2 / \mathrm{FiO} 2 \\
\text { at } 72 \text { hours } \\
\text { (mmHg) }\end{array}$ & $\begin{array}{l}196 \pm 78(27), 170 \pm \\
65(27)\end{array}$ & $\begin{array}{l}239 \pm 91(18), 175 \pm \\
62(18)\end{array}$ & $\begin{array}{l}166 \pm 70(167) \\
157 \pm 68(152)\end{array}$ & $\begin{array}{l}197.8 \pm 74.6 \\
(330), 186.6 \pm \\
75.6(272)\end{array}$ \\
\hline
\end{tabular}

NMBA, neuromuscular blocking agent; ARDS, acute respiratory distress syndrome; NA, not available; SAPS II, simplified acute physiology score II; SOFA, Sequential Organ Failure Assessment; APACHE III, acute physiology, age, and chronic health evaluation III 


\begin{tabular}{|c|c|c|c|c|}
\hline Trial & Gainner 2004 & Forel 2006 & $\begin{array}{l}\text { ACURASYS } \\
\text { Trial } 2010\end{array}$ & $\begin{array}{l}\text { ROSE Trial } \\
2019\end{array}$ \\
\hline $\begin{array}{l}\text { (1) Driving } \\
\text { Pressure } \\
\text { Baseline } \\
(\mathrm{cmH} 20)\end{array}$ & $\begin{array}{l}14.8 \pm 5.4(28), 14.6 \\
\pm 3.5(28)\end{array}$ & $\begin{array}{l}14.3 \pm 3.8(18), 13.8 \\
\pm 4.9(18)\end{array}$ & $\begin{array}{l}15.8 \pm 4.5 \\
(177), 15.2 \pm \\
4.2(162)\end{array}$ & $\begin{array}{l}12.7 \pm 5.8 \\
(274), 13.1 \pm \\
5.9(266)\end{array}$ \\
\hline $\begin{array}{l}\text { (2) Driving } \\
\text { Pressure } \\
\text { At } 24 \mathrm{~h} \\
(\mathrm{cmH} 2 \mathrm{O})\end{array}$ & $\begin{array}{l}14.6 \pm 5.5(28), 15 \pm \\
4.1(28)\end{array}$ & $\begin{array}{l}13.6 \pm 3.5(18), 14.1 \\
\pm 4.2(18)\end{array}$ & $\begin{array}{l}13.6 \pm 4.3 \\
(172), 12.4 \pm \\
4.4(157)\end{array}$ & $\begin{array}{l}12.8 \pm 4.1 \\
(382), 12.1 \pm \\
4.6(331)\end{array}$ \\
\hline $\begin{array}{l}\text { (3) Driving } \\
\text { Pressure } \\
\text { At } 48 \mathrm{~h} \\
(\mathrm{cmH} 2 \mathrm{O})\end{array}$ & $\begin{array}{l}14.7 \pm 6.3(28), 13.6 \\
\pm 4.2(28)\end{array}$ & $\begin{array}{l}13.8 \pm 4.2(18), 14 \pm \\
4.0(18)\end{array}$ & NA & $\begin{array}{l}13.4 \pm 4.2 \\
(348), 12.6 \pm \\
5.0(297)\end{array}$ \\
\hline \multicolumn{5}{|l|}{ Others } \\
\hline $\begin{array}{l}\text { (1) } \\
\text { Barotrauma } \\
\text { (NMBA vs. } \\
\text { Control }(\mathrm{n} / \mathrm{N}) \text { ) }\end{array}$ & $0 / 28,1 / 28$ & $0 / 18,0 / 18$ & $9 / 177,19 / 162$ & $\begin{array}{l}\text { 20/501 } \\
32 / 505\end{array}$ \\
\hline $\begin{array}{l}\text { (2) } \\
\text { Pneumothorax } \\
\text { (NMBA vs. } \\
\text { Control }(\mathrm{n} / \mathrm{N}) \text { ) }\end{array}$ & $0 / 28,1 / 28$ & $0 / 18,0 / 18$ & $7 / 177,19 / 162$ & $\begin{array}{l}14 / 501 \\
25 / 505\end{array}$ \\
\hline $\begin{array}{l}\text { (3) Days free } \\
\text { of ventilation } \\
\text { at day } 28 \\
\text { (mean } \pm \text { SD } \\
\text { with (no), } \\
\text { NMBA vs } \\
\text { control) }\end{array}$ & $\begin{array}{l}3.7 \pm 7.2(28), 1.7 \pm \\
5.3(28)\end{array}$ & $\begin{array}{l}6.0 \pm 8.6(18), 5.4 \pm \\
6.4(18)\end{array}$ & $\begin{array}{l}10.6 \pm 9.7 \\
(177), 8.5 \pm 9.4 \\
(162)\end{array}$ & $\begin{array}{l}9.6 \pm 10.4 \\
(501), 9.9 \pm \\
10.9(505)\end{array}$ \\
\hline \multicolumn{5}{|c|}{ Adverse reaction } \\
\hline $\begin{array}{l}\text { ICU-acquired } \\
\text { weakness by } \\
\text { day } 28 \\
(\text { NMBA vs. } \\
\text { Control }(\mathrm{n} / \mathrm{N}))\end{array}$ & $0 / 28,0 / 28$ & $1 / 18,1 / 18$ & $28 / 96,25 / 77$ & $22 / 47,14 / 51$ \\
\hline $\begin{array}{l}\text { NMBA, neurom } \\
\text { SAPS II, simplifi } \\
\text { acute physiolog }\end{array}$ & $\begin{array}{l}\text { Ular blocking agent; } \\
\text { acute physiology sc } \\
\text { ge, and chronic hea }\end{array}$ & $\begin{array}{l}\text { S, acute respiraton } \\
\text { II; SOFA, Sequential } \\
\text { evaluation III }\end{array}$ & $\begin{array}{l}\text { ress syndrome; } \\
\text { an Failure Assess }\end{array}$ & , not available; \\
\hline
\end{tabular}


The details of the included studies are provided in Table 1. The years of publication ranged from 2004 to 2019. The sample size varied from 36 to 1006 participants. Of the four included trials, all were multicenter trial and were from same group in France except one, which is from United States [14].

\section{Risk of bias in included studies}

Three trials (75\%) were assessed as high risk of bias concerning blinding of participants and personnel. All four trials $(100 \%)$ had low-risk of bias regarding sequence generation, allocation concealment, blinding of outcomes assessment, incomplete outcome data and selecting reporting (Fig. 2). Accordingly, only one trial was assessed as low risk of bias [10].

\section{NMBA did not decrease 90-day or 28-day mortality in ARDS patients}

Table 1 shows that 90 -day mortality were reported in two trials $[10,14]$ and 28 -day mortality were reported in four trials $[10,12-14]$. Combining all trials demonstrated no statistically significant effect of NMBA on 90-day mortality, with a risk ratio (RR) of $0.91(95 \% \mathrm{Cl} 0.72-1.15, P=57 \%, p=0.41)$, based on data from 1345 participants in two trials. Likewise, no significant differences in 28-day mortality were found between the NMBA and control groups (RR $0.55,95 \% \mathrm{Cl} 0.22-1.12,{ }^{2}=58 \%, p=0.08$ ) (Fig. 3), based on data from 1437 participants in four trials. Results were analysed using a random-effect model because heterogeneity was high. We graded the overall strength of the evidence as moderate (Additional file 2).

The results of TSA indicated the optimal information size was 3771 patients for 90 -day mortality based on $20 \%$ RRR (from a baseline event rate of $40 \%$ ) and more high-quality randomized control trials (RCTs) are needed, since $z$ curve did not cross the general boundary line or any adjusted boundary line favoring the NMBA group or control group (Fig. 4A). The optimal information size was 6458 patients for 28-day mortality based on $20 \%$ RRR (from a baseline event rate of $35 \%$ ). Likewise, more high-quality randomized control trials (RCTs) are needed (Fig. 4B).

\section{NMBA improved PaO2/FiO2 ratio at 72 hours in ARDS patients}

For oxygenation, there were four trials $[10,12-14]$ that reported $\mathrm{PaO} 2 / \mathrm{FiO} 2$ ratio at 24 hours and 72 hours, and three trials [12-14] that reported $\mathrm{PaO} 2 / \mathrm{FiO} 2$ ratio at 48 hours. The pooled $\mathrm{MD}$ for $\mathrm{PaO} / \mathrm{FiO} 2$ at 72 hours compared to the control was $15.21\left(95 \% \mathrm{Cl} 1.90-28.52, P^{2}=36 \%, p=0.03\right)$. We graded strength of the evidence as high (Additional file 2). NMBA did not improve PaO2/FiO2 ratio at 24 hours (MD 7.76, $95 \% \mathrm{Cl}-3.74-19.27, P^{2}=33 \%, p=0.19$ ) or 48 hours (MD 29.77, 95\% Cl -4.68-64.27, $P=76 \%, p=0.09$ )

(Fig. 5). The results of TSA indicated the optimal information size was 1583 patients for $\mathrm{PaO2} / \mathrm{FiO} 2$ ratio at 72 hours and more high-quality RCTs are needed. (Additional file 1: Figure S1) 
The control group showed lower driving pressure compared with NMBA group at $\mathbf{2 4}$ hours and $\mathbf{4 8}$ hours in ARDS patients

For driving pressure, there were four trials $[10,12-14]$ that reported driving pressure at 24 hours, and three trials [12-14] that reported driving pressure at 48 hours. Results were analysed using a fixed-effect model because there were no statistically significant heterogeneity $\left(P^{2}=0\right)$. There are no significant difference in driving pressure at baseline between groups ( $M D 0.18,95 \% \mathrm{Cl}-0.46-0.81, p=0.59)$. Amazingly, the results showed lower driving pressure in the control group compared with NMBA group at 24 hours (MD 0.75, $95 \% \mathrm{Cl} 0.24-1.26, p=0.004$ ) and 48 hours (MD 0.75, 95\% Cl 0.08-1.43, $p=0.03$ ) (Fig. 6). We graded the overall strength of the evidence as high (Additional file 2). The results of TSA indicated the cumulative $z$ curve crossed both the conventional boundary for benefit and adjusted boundary line favoring the control group. Thus, further trials were not required and were unlikely to alter the conclusions (Additional file 1: Figure S2).

\section{NMBA decrease the incidence of barotrauma and pneumothorax in patients with ARDS}

The RR estimate for the incidence of barotrauma in patients treated with NMBA compared with control group was $0.55(95 \% \mathrm{Cl} 0.35-0.85, p=0.007)$. Moreover, the RR estimate for the incidence of pneumothorax in patients treated with NMBA compared with control group was $0.46(95 \% \mathrm{Cl} 0.28-0.76, p$ $=0.002$ ) (Fig. 7). We graded the overall strength of the evidence as high (Additional file 2). The results of TSA indicated the cumulative $z$ curve crossed both the conventional boundary for benefit and adjusted boundary line favoring the NMBA group. Thus, further trials were not required and were unlikely to alter the conclusions (Additional file 1: Figure S3).

NMBA did not decrease the ventilator-free days at 28 days in ARDS patients

Four studies [10,12-14] included 1437 patients provided data on ventilator-free days at 28 days. No significant differences in ventilator-free days were found between the NMBA and control groups (MD $0.86,95 \% \mathrm{Cl}-0.61-2.33, P^{2}=34 \%, p=0.25$ ) (Fig. 8). We graded the overall strength of the evidence as moderate (Additional file 2).

\section{NMBA did not increase ICU-acquired weakness by 28 days in ARDS patients}

When pooled together, the four studies $[10,12-14]$ included 363 patients and showed there are no statistically significant difference between NMBA and control groups (RR $1.20,95 \% \mathrm{Cl} 0.72-1.98, \mathrm{I}^{2}=38 \%$, $p=0.49$ ) (Fig. 9). We graded the overall strength of the evidence as moderate (Additional file 2). The results of TSA indicated the optimal information size was 2083 patients for ICU-acquired weakness by 28 days based on $20 \%$ RRR (from a baseline event rate of $30 \%$ ) and more high-quality randomized control 
trials (RCTs) are needed, since $z$ curve did not cross the general boundary line or any adjusted boundary line favoring the NMBA group or control group. (Additional file 1: Figure S4)

\section{Discussion}

The results of this systematic review and meta-analysis provide an evidence summary to inform clinicians regarding decisions to early use NMBA in moderate to severe ARDS patients. We found that assignment to treatment with NMBA did not decrease 90-day or 28-day mortality. Although improved oxygenation and lower incidence of barotrauma and pneumothorax in NMBA group, ventilator-free days at 28 days were not increased in patients assigned to NMBA. Significantly, NMBA exposure has no correlation with the increased incidence of ICU-acquired weakness in ARDS patients. Of note, the NMBA group exhibits higher driving pressure compared with control group, which might negate the potential benefits of NMBA.

The mechanisms underlying the therapeutic effects of NMBA in ARDS remain unclear. Previous systematic review demonstrate that early use of NMBA can improve oxygenation [17]. As shown in this meta-analysis, early use of NMBA indeed improve $\mathrm{PaO} 2 / \mathrm{FiO} 2$ ratio at 72 hours in ARDS patients, which is consistent with the current evidence [17]. However, we did not find survival benefit of early NMBA for ARDS even if $\mathrm{PaO} 2 / \mathrm{FiO} 2$ ratio was improved. It should be noted that the improved oxygenation is not necessarily correlated with improved survival. Furthermore, it is always important to remember to exercise caution with regarding oxygenation as a meaningful outcome variable in ARDS [18].

Another probable mechanism underlying the therapeutic effects of NMBA in ARDS is that early use of NMBA reduce ventilator dyssynchrony in ARDS patients $[19,20]$. Since major concern in mechanically ventilated patients is the risk of ventilator-induced lung injury [21]. Especially, spontaneous ventilation superimposed on mechanical ventilation may result in a high respiratory drive and breathe with large tidal volumes, which may worsen lung injury including barotrauma $[22,23]$. The results of this study also indicate that early use of NMBA in ARDS patients decrease the incidence of barotrauma and pneumothorax when compared with usual care. Notably, dyssynchrony and spontaneous respiratory efforts during the treatment of NMBA on ARDS were not monitored formally in our included trials. Consequently, we have also explored the association of prognosis with possible physiological "markers" that identify risk of injury, such as the driving pressure [24]. The most striking result to emerge from the data is that the control group shows lower driving pressure compared with NMBA group, which means the control group is associated with increased survival thereby confounding the impact of the intervention. Thus, in our view, the 90-day or 28-day mortality should be adjusted for driving pressure at 48 hour to exclude the effect of driving pressure on mortality. Nevertheless, Guervilly et al [25] reported that there was no change in driving pressure related to NMBA administration. The conflicting results might be due to the limited number of included patients in Guervilly's study.

Intriguingly, experimental studies demonstrate that the beneficial effects of NMBA can largely be attributed to the result of modulation of inflammation and injury or even unexplored mechanisms instead 
of its impact on respiratory muscle pump inactivation [26]. Besides, NMBA attenuate endothelial and epithelial injury merely in patients with a $\mathrm{PaO} 2 / \mathrm{FiO} 2$ ratio $\leq 120 \mathrm{mmHg}$ and ventilated with low tidal volumes [27]. Given the lack of effect on mortality of very potent anti-inflammatory agents in previous studies $[4,5,28]$, this seems unlikely to be ultimate mechanism.

Benefits of NMBA use in ARDS patients must be weighed against potential harms [29]. The most concerning side-effect of neuromuscular blockade is the ICU acquired weakness [30]. Consistent with previous meta-analysis studies [31, 32], no evidence for ICU acquired weakness were found in the present study. Risk for ICU acquired weakness is increased with prolonged mechanical ventilation [33]. Here, our results showed that early use of NMBA did not lead to longer ventilation duration of ARDS patients, possibly due to short duration of blockade (48 hours). Although there is limited evidence of NMBA for efficacy beyond short-term physiologic improvement, web survey shows that clinicians are seeking to optimize the use of NMBA in ARDS, including types, dosing, duration [34]. It has been reported that paralysis can be continued beyond 48 hours without increasing the overall mortality [35], while whether longer or shorter infusions of NMBA would provide additional benefit or change the prevalence of ICUacquired weakness is unknown. Moreover, when compared with vecuronium [36] or atracurium [37], cisatracurium, used in all of our included trials, was not associated with a difference in mortality, which suggest that those short-term positive outcomes were not cisatracurium-specific. Thus, a more economical selection of neuromuscular blocking agents in clinical settings should be considered in future.

Taken together, even though the evidences supporting NMBA use in ARDS patients remains relatively sparse, our meta-analysis are able to generate hypotheses that may be tested in future investigation. In the view of ventilator dyssynchrony, neuromuscular blockade should be titrated to ventilator synchrony instead of train of four monitoring, which is not correlate with gas exchange in patients with ARDS [38]. On the one hand, robust parameter are required to be sensitive to the occurrence of patient-ventilator dyssynchrony. On the other hand, maybe clinicians should use NMBA in ARDS patient according to the density or intensity of ventilator dyssynchrony especially those ARDS patients with high respiratory drive instead of severity of illness (PaO2/FiO2 $\leq 150 \mathrm{mmHg}$ ).

Several limitations of the present study should be concerned. Firstly, not all trials reported data on every outcome of interest. Secondly, the trials included a span of 15 years in which ICU practices have changed in the management of ARDS. For instance, the sedation targets used in the control group of ROSE trial [14] were lighter than those used in the ACURASYS trial [10]. Finally, as with all meta-analyses, the strength of conclusions that can be drawn are dependent on the strength of the included trials.

\section{Conclusions}

Based on the current available data, neuromuscular blockade in moderate to severe ARDS did not decrease 90-day or 28-day mortality. Although improved oxygenation and lower incidence of barotrauma and pneumothorax in NMBA group, ventilator-free days at 28 days were not increased in patients 
assigned to NMBA. Fortunately, the use of NMBA was not associated with increased incidence of ICUacquired weakness. Further large-scale, multicenter studies are needed to confirm our results.

\section{Declarations}

\section{Ethics approval and consent to participate}

Each enrolled trial was approved by the corresponding institutional ethical committee, and all participants provided written informed consent.

\section{Consent for publication}

Not applicable.

\section{Availability of data and materials}

Not applicable.

\section{Competing interests}

The authors declare that they have no competing interests.

\section{Funding}

The study is supported by the National Natural Science Foundation of China (No. 81801897, 31800682) and the Priority Academic Program Development of Jiangsu Higher Education Institutions (Integration of Chinese and Western Medicine).

\section{Authors' contributions}

X.P.X and X.W.G had full access to all of the data in the study and takes responsibility for the integrity of the data and the accuracy of the data analysis. X.C.Z. contributed to study design; completed the literature search, data collection, data analysis, and data interpretation; and drafted the first version of the manuscript. D.K.L and F.F.G contributed substantially to the study design, data collection, data analysis and interpretation, and revised the manuscript.

\section{Acknowledgments}

We are grateful to the investigators and clinical trials groups of all the trials included in this study for providing access to their trial data.

\section{Abbreviations}

NMBA 
neuromuscular blocking agent; RR:relative risk; MD:mean difference; ARDS:acute respiratory distress syndrome; RCTs:randomized clinical trials; TSA:trial sequential analysis; RRR:relative risk reduction; Cl:confidence intervals

\section{References}

1. Force ADT, Ranieri VM, Rubenfeld GD, et al. Acute respiratory distress syndrome: the Berlin Definition. JAMA. 2012;307:2526-33.

2. Fan E, Brodie D, Slutsky AS. Acute Respiratory Distress Syndrome: Advances in Diagnosis and Treatment. JAMA. 2018;319:698-710.

3. Gao Smith F, Perkins GD, Gates S, et al. Effect of intravenous beta-2 agonist treatment on clinical outcomes in acute respiratory distress syndrome (BALTI-2): a multicentre, randomised controlled trial. Lancet. 2012;379:229-35.

4. McAuley DF, Laffey JG, O'Kane CM, et al. Simvastatin in the acute respiratory distress syndrome. N Engl J Med. 2014;371:1695-703.

5. National Heart L, Blood Institute ACTN, Truwit JD, et al. Rosuvastatin for sepsis-associated acute respiratory distress syndrome. N Engl J Med. 2014;370:2191-200.

6. McAuley DF, Cross LM, Hamid U, et al. Keratinocyte growth factor for the treatment of the acute respiratory distress syndrome (KARE): a randomised, double-blind, placebo-controlled phase 2 trial. Lancet Respir Med. 2017;5:484-91.

7. Gebistorf F, Karam O, Wetterslev J, et al. Inhaled nitric oxide for acute respiratory distress syndrome (ARDS) in children and adults. Cochrane Database Syst Rev. 2016:CD002787.

8. Meduri GU, Bridges L, Shih MC, et al. Prolonged glucocorticoid treatment is associated with improved ARDS outcomes: analysis of individual patients' data from four randomized trials and trial-level meta-analysis of the updated literature. Intensive Care Med. 2016;42:829-40.

9. Fan E, Del Sorbo L, Goligher EC, et al An Official American Thoracic Society/European Society of Intensive Care Medicine/Society of Critical Care Medicine Clinical Practice Guideline. Mechanical Ventilation in Adult Patients with Acute Respiratory Distress Syndrome. Am J Respir Crit Care Med. 2017;195:1253-63.

10. Papazian L, Forel JM, Gacouin A, et al. Neuromuscular blockers in early acute respiratory distress syndrome. N Engl J Med. 2010;363:1107-16.

11. Murray MJ, DeBlock H, Erstad B, et al. Clinical Practice Guidelines for Sustained Neuromuscular Blockade in the Adult Critically III Patient. Crit Care Med. 2016;44:2079-103.

12. Forel JM, Roch A, Marin V, et al. Neuromuscular blocking agents decrease inflammatory response in patients presenting with acute respiratory distress syndrome. Crit Care Med. 2006;34:2749-57.

13. Gainnier M, Roch A, Forel JM, et al. Effect of neuromuscular blocking agents on gas exchange in patients presenting with acute respiratory distress syndrome. Crit Care Med. 2004;32:113-9. 
14. National Heart L, Blood Institute PCTN, Moss M, et al. Early Neuromuscular Blockade in the Acute Respiratory Distress Syndrome. N Engl J Med. 2019;380:1997-2008.

15. Neto AS, Pereira VG, Esposito DC, et al. Neuromuscular blocking agents in patients with acute respiratory distress syndrome: a summary of the current evidence from three randomized controlled trials. Ann Intensive Care. 2012;2:33.

16. Guyatt GH, Oxman AD, Vist GE, et al. GRADE: an emerging consensus on rating quality of evidence and strength of recommendations. BMJ. 2008;336:924-6.

17. Tao W, Yang LQ, Gao J, et al. Neuromuscular blocking agents for adult patients with acute respiratory distress syndrome: A meta-analysis of randomized controlled trials. J Trauma Acute Care Surg. 2018;85:1102-9.

18. Kacmarek RM, Berra L. Prediction of ARDS outcome: what tool should I use? Lancet Respir Med. 2018;6:253-4.

19. Beitler JR, Sands SA, Loring SH, et al. Quantifying unintended exposure to high tidal volumes from breath stacking dyssynchrony in ARDS: the BREATHE criteria. Intensive Care Med. 2016;42:1427-36.

20. Sottile PD, Albers D, Higgins C, et al. The Association Between Ventilator Dyssynchrony, Delivered Tidal Volume, and Sedation Using a Novel Automated Ventilator Dyssynchrony Detection Algorithm. Crit Care Med. 2018;46:e151-e7.

21. Slutsky AS, Ranieri VM. Ventilator-induced lung injury. N Engl J Med. 2013;369:2126-36.

22. Yoshida T, Uchiyama A, Matsuura N, et al. Spontaneous breathing during lung-protective ventilation in an experimental acute lung injury model: high transpulmonary pressure associated with strong spontaneous breathing effort may worsen lung injury. Crit Care Med. 2012;40:1578-85.

23. Yoshida T, Torsani V, Gomes S, et al. Spontaneous effort causes occult pendelluft during mechanical ventilation. Am J Respir Crit Care Med. 2013;188:1420-7.

24. Amato MB, Meade MO, Slutsky AS, et al. Driving pressure and survival in the acute respiratory distress syndrome. N Engl J Med. 2015;372:747-55.

25. Guervilly C, Bisbal M, Forel JM, et al. Effects of neuromuscular blockers on transpulmonary pressures in moderate to severe acute respiratory distress syndrome. Intensive Care Med. 2017;43:408-18.

26. Fanelli V, Morita Y, Cappello P, et al. Neuromuscular Blocking Agent Cisatracurium Attenuates Lung Injury by Inhibition of Nicotinic Acetylcholine Receptor-alpha1. Anesthesiology. 2016;124:132-40.

27. Sottile PD, Albers D, Moss MM. Neuromuscular blockade is associated with the attenuation of biomarkers of epithelial and endothelial injury in patients with moderate-to-severe acute respiratory distress syndrome. Crit Care. 2018;22:63.

28. Raghavendran K, Pryhuber GS, Chess PR, et al. Pharmacotherapy of acute lung injury and acute respiratory distress syndrome. Curr Med Chem. 2008;15:1911-24.

29. Syed A, Kobzik A, Huang DT. Role of Pharmacologic Paralysis in Acute Respiratory Distress Syndrome. Semin Respir Crit Care Med. 2019;40:101-13. 
30. Kress JP, Hall JB. ICU-acquired weakness and recovery from critical illness. N Engl J Med. 2014;370:1626-35.

31. Puthucheary Z, Rawal J, Ratnayake G, et al. Neuromuscular blockade and skeletal muscle weakness in critically ill patients: time to rethink the evidence? Am J Respir Crit Care Med. 2012;185:911-7.

32. Price DR, Mikkelsen ME, Umscheid CA, et al. Neuromuscular Blocking Agents and Neuromuscular Dysfunction Acquired in Critical Illness: A Systematic Review and Meta-Analysis. Crit Care Med. 2016;44:2070-8.

33. De Jonghe B, Bastuji-Garin S, Durand MC, et al. Respiratory weakness is associated with limb weakness and delayed weaning in critical illness. Crit Care Med. 2007;35:2007-15.

34. Alhurani RE, Oeckler RA, Franco PM, et al. Refractory Hypoxemia and Use of Rescue Strategies. A U.S. National Survey of Adult Intensivists. Ann Am Thorac Soc. 2016;13:1105-14.

35. Barmparas G, Dhillon NK, Tatum JM, et al. Extended neuromuscular blockade in acute respiratory distress syndrome does not increase mortality. J Surg Res. 2018;231:434-40.

36. Sottile PD, Kiser TH, Burnham EL, et al. An Observational Study of the Efficacy of Cisatracurium Compared with Vecuronium in Patients with or at Risk for Acute Respiratory Distress Syndrome. Am J Respir Crit Care Med. 2018;197:897-904.

37. Moore L, Kramer CJ, Delcoix-Lopes S, et al. Comparison of Cisatracurium Versus Atracurium in Early ARDS. Respir Care. 2017;62:947-52.

38. Groetzinger LM, Rivosecchi RM, Kane-Gill SL, et al. Association Between Train-of-Four Values and Gas Exchange Indices in Moderate to Severe Acute Respiratory Distress Syndrome. Ann Pharmacother. 2016;50:1009-15.

\section{Figures}



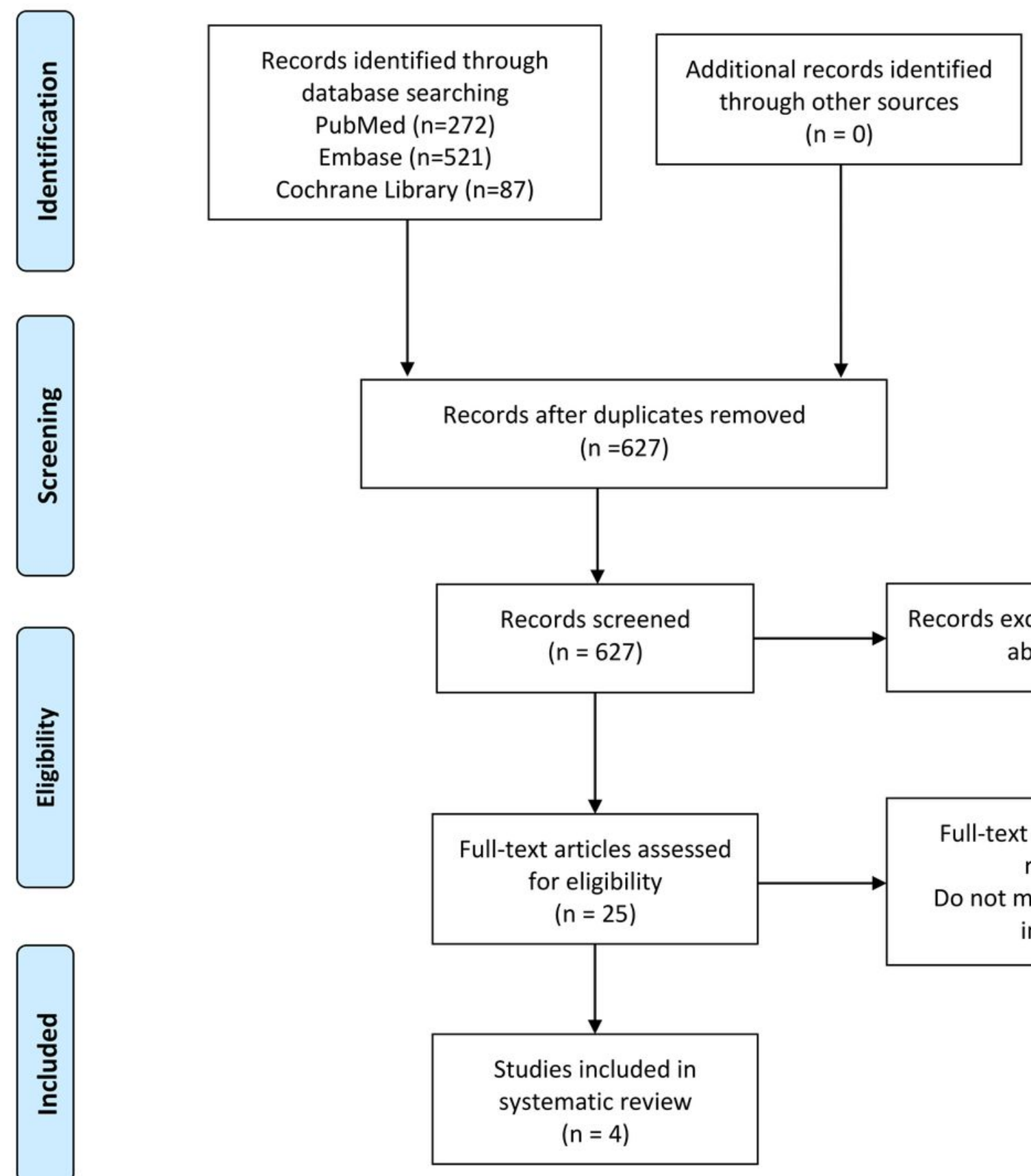

Records excluded based on titles and abstracts $(n=602)$

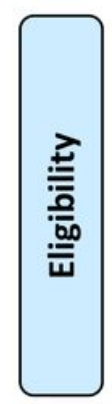

Full-text articles excluded, with reasons $(n=21)$

Do not meet inclusion criteria of intervention $=21$

\section{Figure 1}

Flow diagram (PRISMA) of trial selection. 


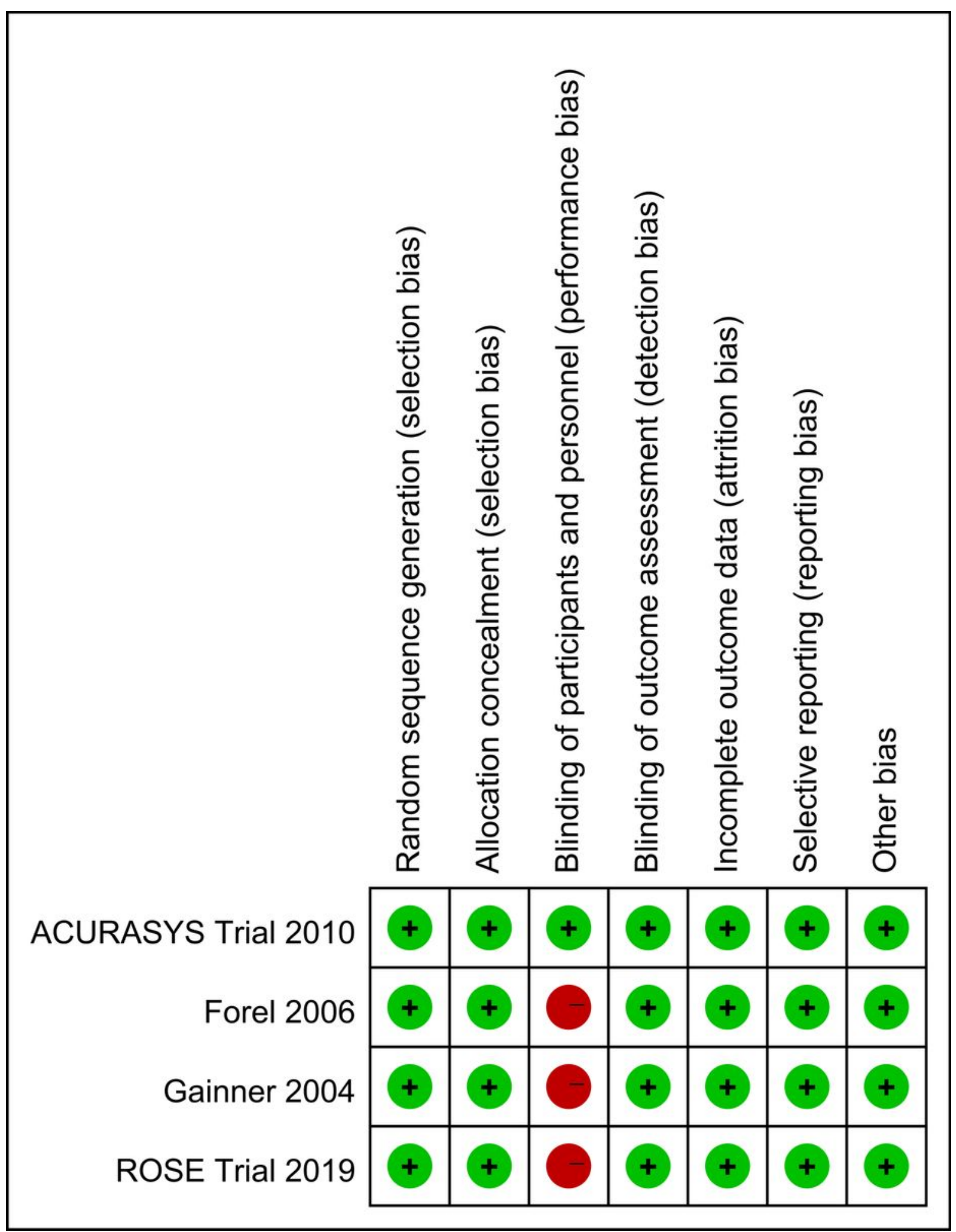

Figure 2

Risk of bias summary for each included study. Red (-): high risk of bias; Green (+): low risk of bias. 
NMBA Control Risk Ratio Risk Ratio

Study or Subgroup

Events Total Events Total Weight M-H. Random. 95\% Cl Year

1.1.1 90-d Mortality

ACURASYS Trial 2010

$\begin{array}{rrrrr}56 & 177 & 66 & 162 & 37.0 \% \\ 213 & 501 & 216 & 505 & 63.0 \% \\ & 678 & & 667 & 100.0 \%\end{array}$

$0.78[0.58,1.03] 2010$

ROSE Trial 2019 269 282

Total events

$\mathrm{Ci}^{2}=2.30, \mathrm{df}=1(\mathrm{P}=0.13) ; \mathrm{I}^{2}=57 \%$

Heterogeneity: $\mathrm{Tau}^{2}=0.02 ; \mathrm{Chi}^{2}=2.30$,
Test for overall effect: $\mathrm{Z}=0.82(\mathrm{P}=0.41)$

1.1.2 28 d Mortality

Gainner 2004

Forel 2006

ACURASYS Trial 2010

ROSE Trial 2019

Subtotal $(95 \% \mathrm{Cl})$

Total events

$\begin{array}{rrrrr}10 & 28 & 17 & 28 & 17.6 \% \\ 5 & 18 & 10 & 18 & 10.2 \% \\ 42 & 177 & 54 & 162 & 30.0 \% \\ 184 & 501 & 187 & 505 & 42.3 \% \\ & 724 & & 713 & 100.0 \% \\ 241 & & 268 & & \end{array}$

$0.59[0.33,1.05] 2004$ $0.50[0.21,1.17] 2006$ $0.71[0.51,1.00] 2010$ $0.99[0.84,1.17] 2019$ $0.76[0.56,1.04]$

Heterogeneity: $\mathrm{Tau}^{2}=0.05 ; \mathrm{Chi}^{2}=7.08, \mathrm{df}=3(\mathrm{P}=0.07) ; \mathrm{I}^{2}=58 \%$

Test for overall effect: $Z=1.72(P=0.08)$

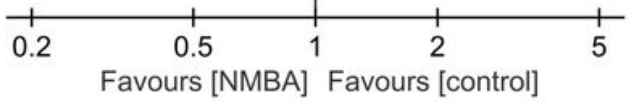

\section{Figure 3}

Meta-analysis of the effect of NMBA on mortality at day 90 and day 28 in ARDS patients. M-H = MantelHaenszel. 

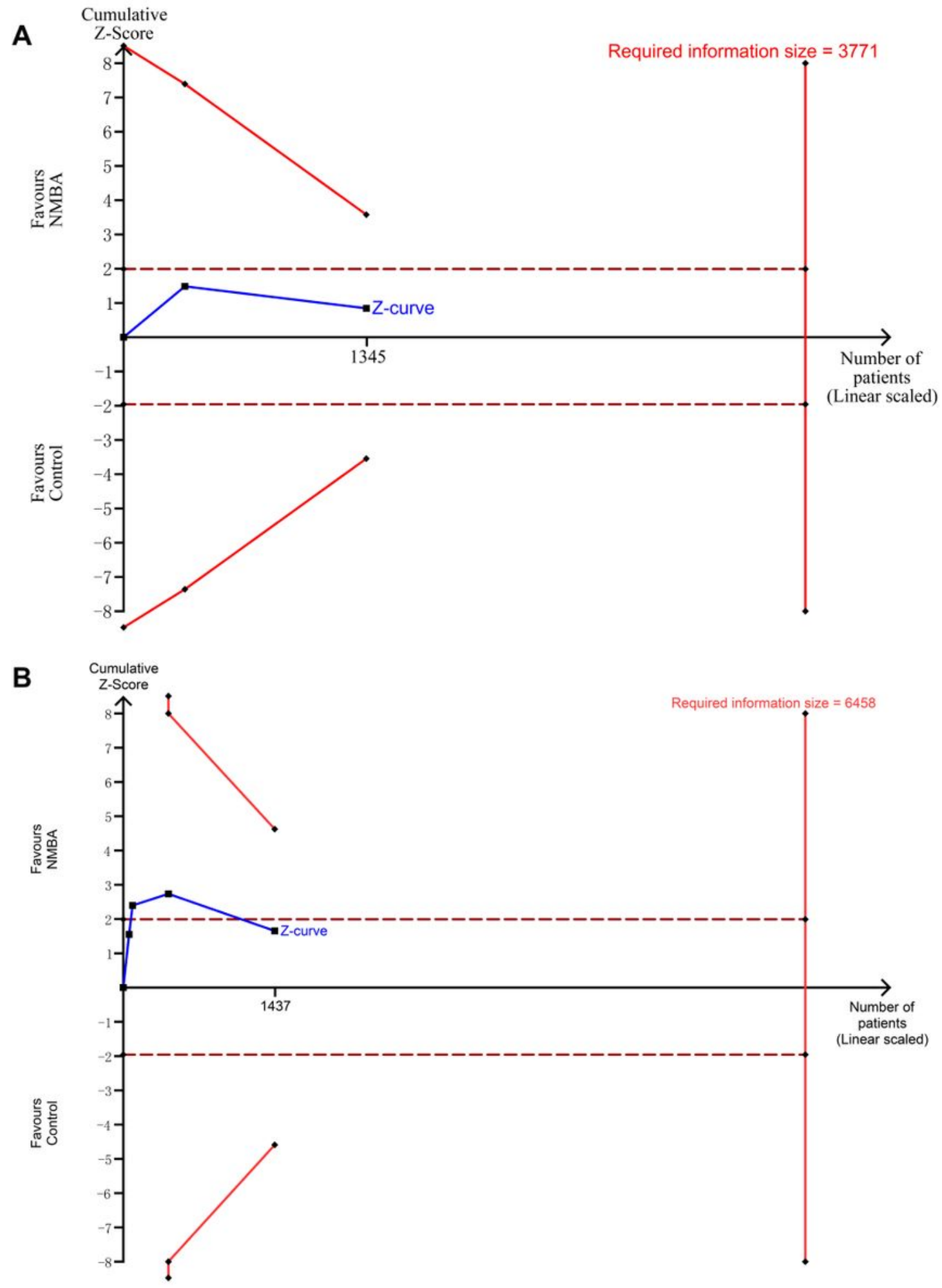

\section{Figure 4}

Trial sequential analysis for effects of NMBA on 90-day mortality (A) and 28-day mortality (B). A: The diversity-adjusted required information size (3771 participants) was based on a relative risk reduction of $20 \%$, an alpha of $5 \%$, a beta of $20 \%$, and an event proportion of $40 \%$ in the control arm. The blue cumulative $z$ curve was constructed using a random effects model. B: The diversity-adjusted required information size (6458 participants) was based on a relative risk reduction of $20 \%$, an alpha of $5 \%$, a beta 
of $20 \%$, and an event proportion of $35 \%$ in the control arm. The blue cumulative $z$ curve was constructed using a random effects model.

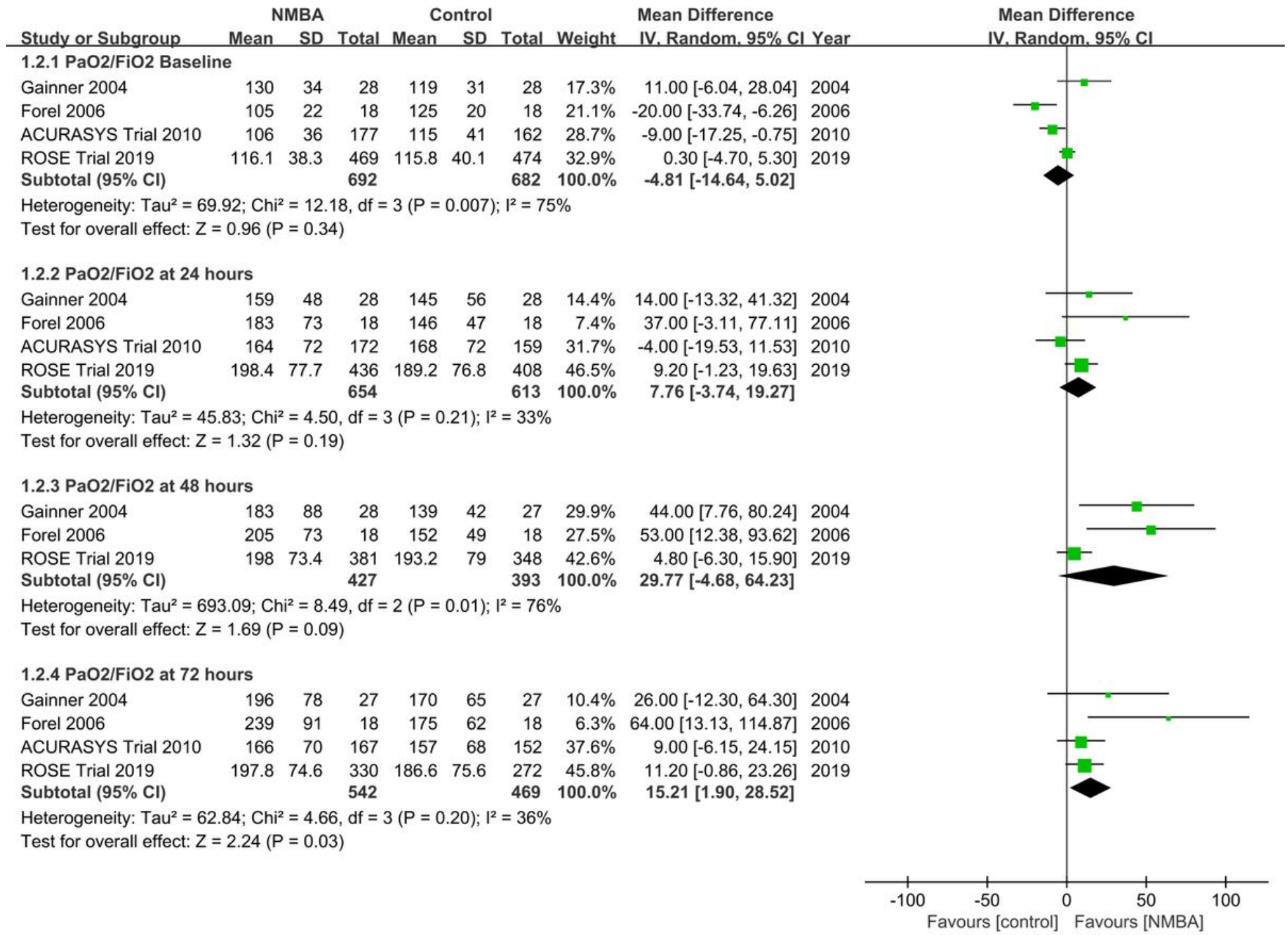

\section{Figure 5}

Meta-analysis of the effect of NMBA on PaO2/FiO2 at 24, 48 and 72 hours after randomization in ARDS patients. IV=Inverse Variance. 


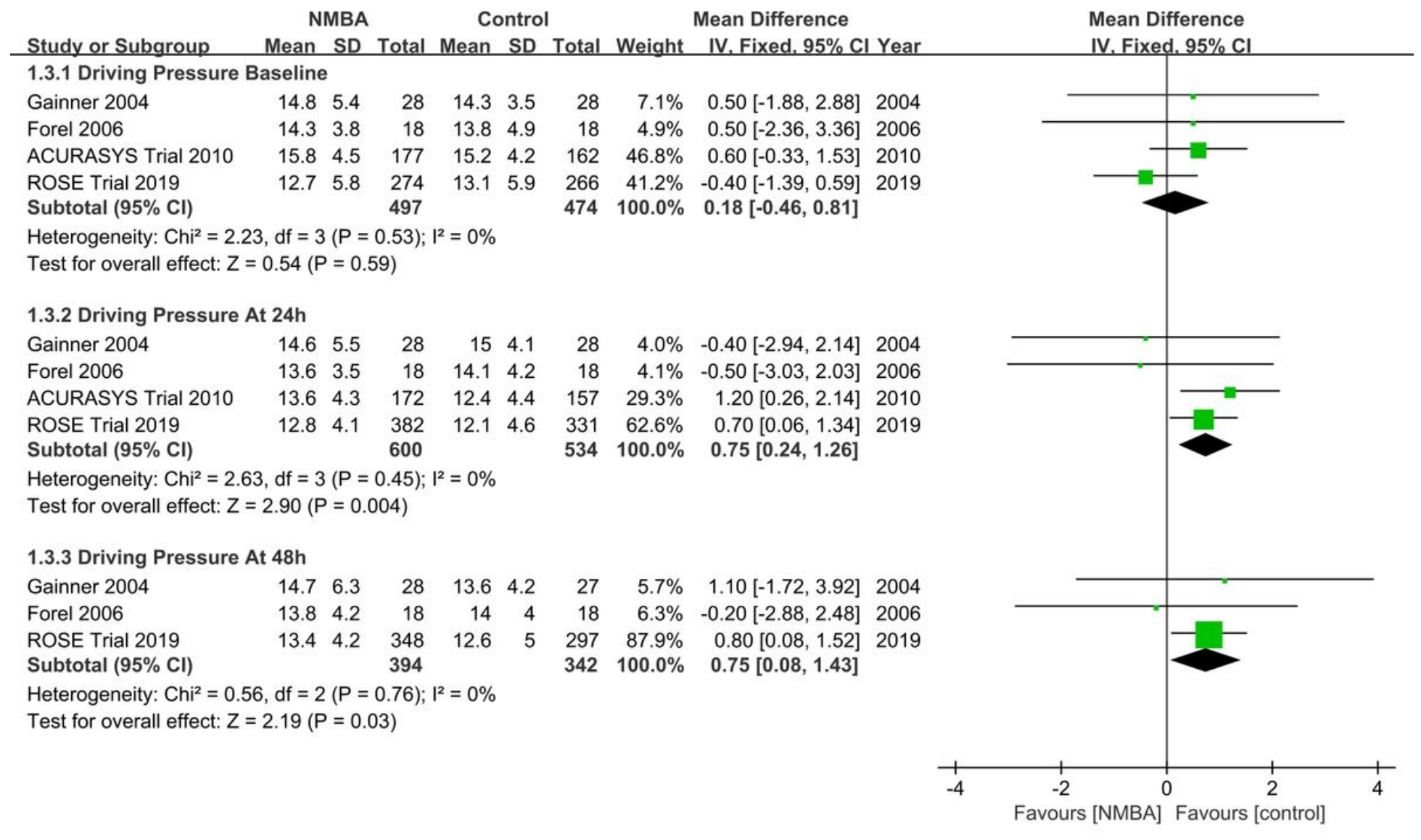

\section{Figure 6}

Meta-analysis of the effect of NMBA on driving pressure at 24 and 48 hours after randomization in ARDS patients. IV=Inverse Variance.

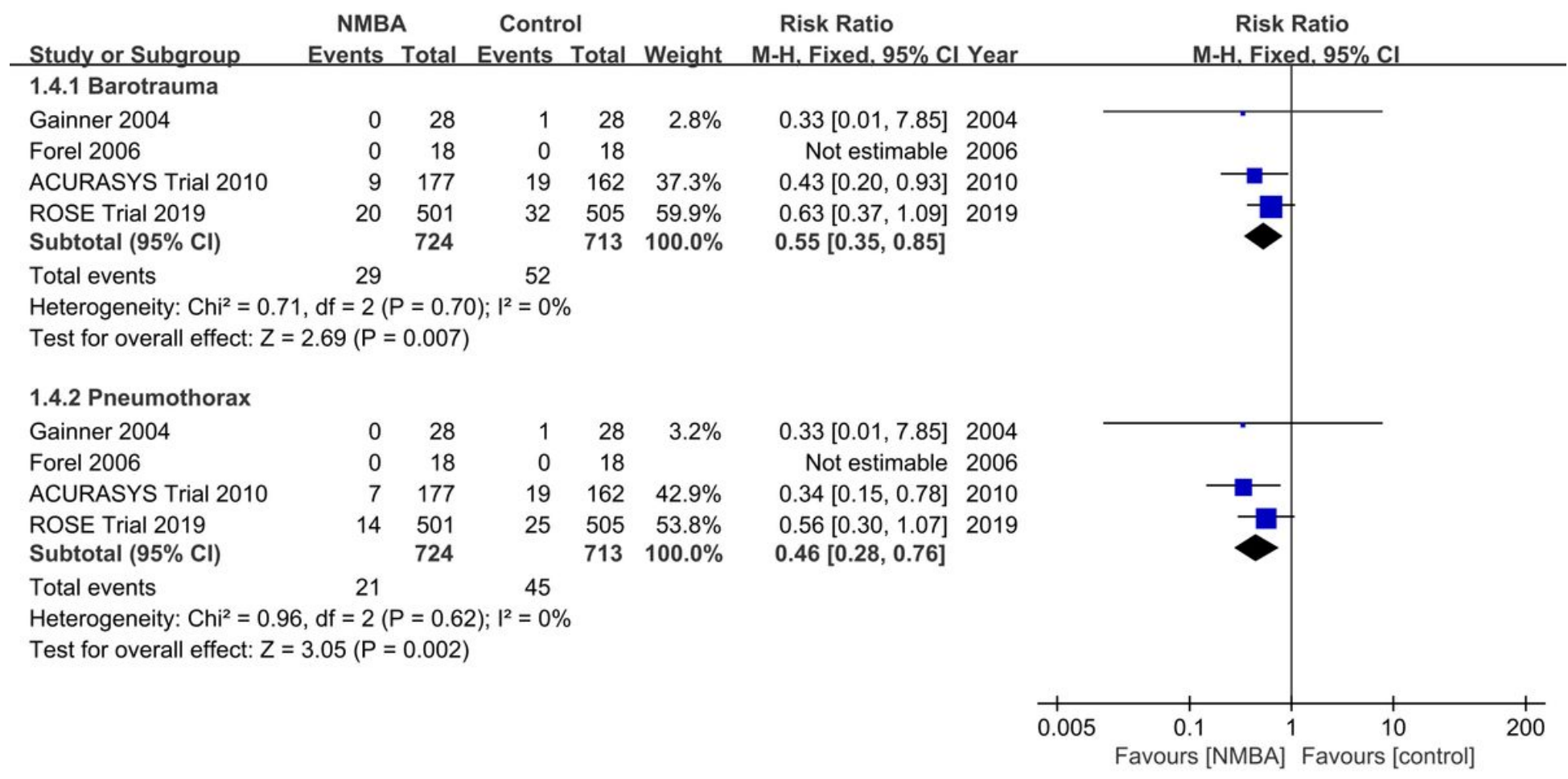




\section{Figure 7}

Meta-analysis of the effect of NMBA on the incidence of barotrauma and pneumothorax in ARDS patients. $\mathrm{M}-\mathrm{H}=$ Mantel-Haenszel.

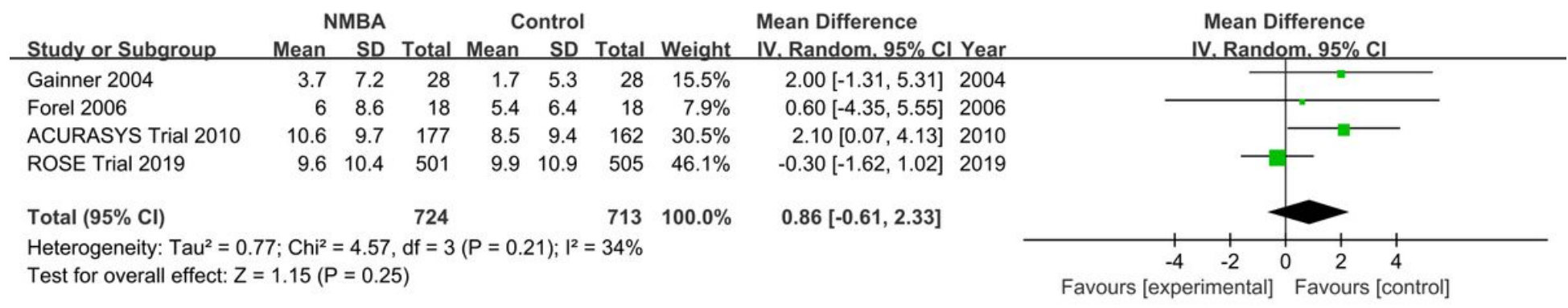

\section{Figure 8}

Meta-analysis of the effect of NMBA on the ventilator-free days at 28 days after randomization in ARDS patients. IV=Inverse Variance.

NMBA

Study or Subgroup

Gainner 2004

Forel 2006

ACURASYS Trial 2010

ROSE Trial 2019

Total $(95 \% \mathrm{Cl})$

Total events

Heterogeneity: $\mathrm{Tau}^{2}=0.07 ; \mathrm{Chi}^{2}=3.21, \mathrm{df}=2(\mathrm{P}=0.20) ; \mathrm{I}^{2}=38 \%$

Test for overall effect: $Z=0.70(P=0.49)$
$174100.0 \%$
Control

Risk Ratio

Risk Ratio M-H, Random, $95 \% \mathrm{Cl}$

$\begin{array}{rrrrr}0 & 28 & 0 & 28 & \\ 1 & 18 & 1 & 18 & 3.4 \% \\ 28 & 96 & 25 & 77 & 52.4 \% \\ 22 & 47 & 14 & 51 & 44.2 \%\end{array}$

Not estimable 2004

$1.00[0.07,14.79] 2006$

$0.90[0.57,1.41] 2010$

$1.71[0.99,2.93] 2019$

$1.20[0.72,1.98]$

\section{Figure 9}

Meta-analysis of the effect of NMBA on ICU-acquired weakness in ARDS patients. $\mathrm{M}-\mathrm{H}=$ MantelHaenszel.

\section{Supplementary Files}

This is a list of supplementary files associated with this preprint. Click to download.

- Additionalfile2TableS1GRADEevidenceprofile.docx

- Additinalfile1FigureS1S4.docx 